\title{
Obesity: The Next Public Health Challenge
}

\author{
Christine M Bond
}

$\mathrm{I}^{\mathrm{n}}$ the past few decades, life expectancy has increased dramatically in developed countries, and many people now have better quality of life at a chronological age that 40 years ago would have seemed unimaginable. We have added both years to life and life to years. These changes are attributable to improved understanding of disease processes and their management. Pharmacotherapies and pharmacists have contributed to these improvements. However, this is only part of the story: much of the changed demographic profile comes from a better understanding of how we can prevent disease through public health approaches to improved lifestyles. In the United Kingdom, smoking prevalence, once $50 \%,{ }^{1}$ is now $16 \%,{ }^{2}$ and in many subsets of the population, it is even lower. Smoking prevalence in Canada is also at an all-time low, an estimated $13 \% .^{3}$ Smoking reductions have translated into reductions in coronary heart disease and cancers; indeed, smoking cessation has been labelled the most costeffective health intervention there is. Pharmacists have contributed greatly to this cultural change.

There is still more work to be done with smoking cessation, but we have an evidence-based, appropriately resourced system in place that we can continue to implement. That is not the case for obesity, widely regarded as the next public health challenge, one to which pharmacists can and should contribute. One in 4 adult Canadians and 1 in 10 children have clinical obesity, ${ }^{4}$ with a significantly higher prevalence among some groups, such as Aboriginal populations. ${ }^{5}$ An estimated 6 million Canadians live with obesity and may require immediate support in managing and controlling their weight. Although obesity is less of a problem in Canada than in the United States, where more than one-third of adults ${ }^{6}$ and up to one-fifth of children are obese, ${ }^{7}$ Canada does need to address this potential time bomb. A 2010 report estimated the direct health care costs of overweight and obesity in Canada to be $\$ 6$ billion, about $4.1 \%$ of the total health care budget. ${ }^{4}$ Furthermore, this estimate does not account for productivity losses, reductions in tax revenues, or psychosocial costs. ${ }^{4}$ At a high-level meeting of the United Nations General
Assembly in 2011, on the prevention and control of communicable disease, ${ }^{8}$ the rise in prevalence of obesity among infants, children, and adolescents was highlighted as a particular concern, and implementation of the World Health Organization's Global Strategy on Diet, Physical Activity and Health was recommend-

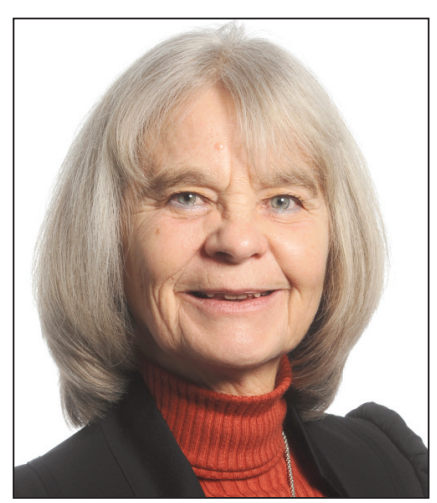
ed, including (where appropriate) policies and actions to promote healthy diets and increase physical activity. Obese children face immediate health problems, achieve fewer standard educational targets, and have poorer quality of life. In addition, the evidence suggests that an obese child will become an obese adult, carrying the risk of future development of type 2 diabetes mellitus, heart disease, stroke, dementia, kidney disease, and some cancers.

Comprehensive public, private, and nongovernmental initiatives on obesity prevention and treatment are urgently needed. Pharmacists are already involved in providing weight management programs, ${ }^{9}$ but there is insufficient evidence to demonstrate their effectiveness, ${ }^{10}$ and the contribution they make to tackling obesity warrants further exploration. ${ }^{11}$ There is evidence that family physician-led screening and brief motivational advice are effective, ${ }^{12}$ and there is no reason why pharmacists working in the community could not also deliver such a structured service, giving priority to overweight patients with conditions exacerbated by obesity (e.g., type 2 diabetes and osteoarthritis). As with smoking cessation progams, pharmacists can effectively deliver lifestyle change interventions, allowing physicians to focus on more complex clinical aspects of obesity. However, lifestyle options, including but not limited to diet and exercise, can only go so far. Once a patient is seriously or morbidly obese, multifaceted approaches are needed. Similar to smoking 
cessation, where behavioural approaches generally complement pharmacological treatment, management of adult obesity may require pharmacological and surgical as well as behavioural approaches. Orlistat, which reduces the amount of fat the body absorbs from food, is now widely used with success and, apart from minor side effects, is usually well tolerated. Although predominantly a prescription medicine, it is available as an overthe-counter product in many countries, including the United States, and is available online in Canada. Other obesity treatments act on the central nervous system by reducing appetite (e.g., lorcaserin or phentermine) and inducing satiety. Such drugs are more likely to have adverse side effects, have significant drug interactions, and be contraindicated, for example, in patients with heart disease. There are opportunities for pharmacists to advise on the most appropriate treatments, highlight potential drug interactions, and identify patients with contraindications. Furthermore, pharmacists can warn people about the dangers of miracle weight loss cures and the potential dangers of buying products online. Thus, all pharmacists could help people to manage their weight.

The question is not whether there could be a role for pharmacists in the management of the obesity epidemic, but whether such a role can be implemented. Can pharmacists adapt the behavioural change techniques used in smoking cessation to a different, potentially more sensitive context? Will the public accept such pharmacy interventions? Do pharmacists have the detailed knowledge to give advice to medical colleagues on the best pharmacological approach? Will pharmacists be recognized by policy-makers and managers as part of the specialist team? These are the key questions and challenges for educators, researchers, and health care managers to address.

All of this is playing out against a background of an obesogenic environment, and a recognition and understanding that some individuals are genetically predisposed to obesity. Fast food and fizzy drinks are consumed daily by many people, and there are barriers (e.g., the weather) and disincentives (e.g., time pressures) to incorporating physical activity such as walking into daily routines. Although early prevention, including changes to the environment and a shift in cultural norms, is the long-term answer, there is an immediate problem to address. A wholesystems approach is required now to deal with current population needs, and it is important that all pharmacists play their part alongside other health care professionals.

\section{References}

1. Adult smoking habits in the UK: 2016 [statistical bulletin]. Newport (Wales): Office for National Statistics; 2017 [cited 2017 Aug 18]. Available from: https://www.ons.gov.uk/peoplepopulationandcommunity/healthandsocialcare/ healthandlifeexpectancies/bulletins/adultsmokinghabitsingreatbritain/2016
2. Smoking rate in UK falls to second-lowest in Europe. The Guardian 2017 Jun 15 [cited 2017 Aug 18]. Available from: https://www.theguardian.com/ society/2017/jun/15/smoking-rate-in-uk-falls-to-second-lowest-in-europe

3. Tobacco use in Canada: highlights. Waterloo $(\mathrm{ON})$ : University of Waterloo, Propel Centre for Population Health Impact; 2017 [cited 2017 Aug 18]. Available from: https:/uwaterloo.ca/tobacco-use-canada/highlights

4. Obesity in Canada [home page on Internet]. Edmonton (AB): Canadian Obesity Network; [cited 2017 Aug 18]. Available from: www.obesitynetwork.ca/ obesity-in-canada

5. Obesity in Canada - prevalence among aboriginal populations. Ottawa (ON): Public Health Agency of Canada; [modified 2011 Jun 23; cited 2017 Aug 8]. Available from: https://www.canada.ca/en/public-health/services/ health-promotion/healthy-living/obesity-canada/prevalence-amongaboriginal-populations.html

6. Overweight and obesity: adult obesity facts. Atlanta (GA): Centers for Disease Control and Prevention; [cited 2017 Aug 18]. Available from: https:// www.cdc.gov/obesity/data/adult.html

7. The state of childhood obesity. In: The state of obesity: better policies for a healthier America [website]. Washington (DC): Trust for America's Health and Robert Wood Johnson Foundation; [updated 2017 Aug; cited 2017 Aug 18]. Available from: www.stateofobesity.org

8. Items 24 and 43d. In: Political declaration of the High-level Meeting of the General Assembly on the Prevention and Control of Non-communicable Diseases [draft resolution submitted by the President of the General Assembly]. New York (NY): United Nations General Assembly; 2011 [cited 2017 Aug 18]. Available from: www.un.org/ga/search/view_doc.asp? symbol=A/66/L.1

9. Murphy AL, Gardner DM. A scoping review of weight bias by community pharmacists towards people with obesity and mental illness. Can Pharm J. 2016;149(4):226-35.

10. Gordon J, Watson M, Avenell A. Lightening the load? A systematic review of community pharmacy-based weight management interventions. Obes Rev. 2011;12(11):897-911.

11. McVey GL, Walker KS, Beyers J, Harrison HL, Simkins SW, RussellMayhew S. Integrating weight bias awareness and mental health promotion into obesity prevention delivery: a public health pilot study. Prev Chronic Dis. 2013 Apr 4;10:E46.

12. Aveyard P, Lewis A, Tearne S, Hood K, Christian-Brown A, Adab P, et al. Screening and brief intervention for obesity in primary care: a parallel, two-arm, randomised trial. Lancet. 2016;388(10059):2492-500.

Christine M Bond, BPharm, PhD, MEd, is Emeritus Professor, Centre of Academic Primary Care, University of Aberdeen, Foresterhill, Aberdeen, Scotland. She is also an Associate Editor with the Canadian Journal Hospital Pharmacy.

Competing interests: None declared.

Address correspondence to:

Professor Christine M Bond

Pharmacy

Centre of Academic Primary Care

Polwarth Building West Block, Room 1.123

Foresterhill, Aberdeen AB25 2ZD

Scotland

e-mail: c.m.bond@abdn.ac.uk 